\title{
Müzik Eğitimi Anabilim Dalı Bina Standartlarının Belirlenmesi
}

\author{
Building Standards of Music Education Departments
}

\author{
Ahmet Suat KARAHAN ${ }^{1}$
}

Özet: Müzik eğitimcisi yetiştirme sürecinde fiziksel imkân ve ders materyal yeterlikleri büyük bir yer ve öneme sahiptir ancak yapılan kaynak taraması sonucunda Türkiye'deki Müzik Eğitimi Anabilim Dalı (MEAD) bina yeterliklerinin bölgesel kapsamda eşit bir dağılım göstermediği ve çeşitli yetersizliklerin olduğu belirlenmiştir. $\mathrm{Bu}$ durumun oluşmasında ise, MEAD binalarının bir standardının olmaması büyük bir etkiye sahiptir.

Araştırmanın amacı, yürürlükte olan Müzik Öğretmenliği Lisans Programı (MÖLP) kapsamında eğitim alan 160 öğrencinin ihtiyaçlarına uygun olarak MEAD binalarının sahip olması gereken özellikleri ve bu özelliklerin standartlarını belirlemektir. Araştırma, hem konuya ilişkin yapılan ilk çalışma olması hem de yürürlükte olan MÖLP'nın daha etkin kullanımına katkıda bulunması açılarından önem taşımaktadır.

Araştırmanın evrenini MÖLP kapsamında 160 öğrenciye hizmet verecek bir MEAD binasında kaç adet Bireysel Çalg1 Odası, Derslik, Orkestra Salonu vb. mekânların olması gerektiğine ilişkin standartlar oluşturmaktadır. Tarama modelinde betimsel yöntemin tercih edildiği araştırmada verilerin bir bölümüne kaynak taraması yöntemiyle ulaşılırken, diğer bir bölümüne ise telefonla görüşme yöntemi kullanılarak ulaşılmıştır. Verilerin işlenmesinde metin analizi yöntemi ve ayrıca SPSS 22 programı kullanılmış ve sonuçlar frekans ve yüzde değerleri üzerinden yorumlanmıştır.

Araştırma sonucunda, MÖLP kapsamında toplam 160 öğrenciye hizmet verecek bir MEAD binasında en az 8 adet Bireysel Piyano dersliğinin (akademisyen odası), en az 17 adet Piyano çalışma odasının, en az 8 adet Bireysel Çalgı dersliğinin, en az 21 adet Bireysel çalgı odasının, en az 8 adet Bireysel Ses Eğitimi dersliğinin, en az 9 adet Bireysel Ses Eğitimi çalışma odasının, MIOY, Armoni ve Eşlik ders dişı çalışmalar için en az 18 adet piyano çalışma odasının, en az 1 adet Orkestra dersliği ve Orkestra çalışma salonunun, en az 1 adet Oda müziği dersliği ve çalışma salonunun, en az 1 adet Koro dersliği ve çalışma salonunun ve en az 1 adet Elektronik Org Laboratuarına ve tüm diğer toplu dersler için en az 3 adet dersliğin, en az 1

\begin{abstract}
Physical facilities and course materials have a great place and importance in the training process of music teachers; however, as a result of the literature review, it was found out that physical facilities of buildings at the Departments of Music Education in Turkey did not have an equal distribution regionally and had various inadequateness, because there were no standards for the buildings of Music Education Departments.
\end{abstract}

The aim of the present research is to determine features of the buildings of the Music Education Departments according to the needs of 160 undergraduate music students and to determine the standards of these features. The research is important for being the first study on the subject and for its contribution to more effective use of the present Music Education Undergraduate Program.

Research population includes the standards about the needed numbers of Instrument Rooms, Classrooms, Orchestra Halls and etc. places at a Department of Music Education for 160 undergraduate music students. In the research in which the descriptive survey model was preferred, some of the data was obtained through literature review and the others via the telephone interview. For the process of data, text analysis method and SPSS 22 program were used and the results were commented as frequency and percentage values.

As a result of the study, it was concluded that for a 160 undergraduate music student-building at the Department of Music Education there should be at least 8 Individual Piano Classes (academician room), at least 17 Piano Rooms, at least 8 Individual Instrument Classes, at least 21 Individual Instrument Rooms, at least 8 Individual Voice Training Classes, at least 9 Individual Voice Training Study Rooms, at least 18 Piano-Practices Rooms for extracurricular Ear Training, Harmony and Accompaniment lessons, at least 1 Orchestra Class and Orchestra Study Hall, at least 1 Chamber Music Classroom and study hall, at least 1 Choir Classroom and study hall, and at least 1 Electronic Organ Laboratory, and at least 3 classrooms for all other lessons, at least 1 Concert Hall and Recording Studio, at least 1 Computer

\footnotetext{
1 Harran Üniversitesi
} 
adet Konser Salonu ve ses kayıt stüdyosunun, en az 1 adet bilgisayar laboratuarının ve 1 adet bilişim laboratuarının olması gerektiği belirlenmiştir.

Anahtar Kelimeler: Müzik Öğretmenliği Lisans Programı, Müzik Eğitimi Anabilim Dal, Bina Özellikleri ve Standartlart laboratory and 1 IT laboratory.

Key Words: Music Education Undergraduate Program, Department of Music Education, Building Features and Standards

\section{Giriş}

Müzik eğitimcilerinin mesleki yaşantılarında başarılı olabilmeleri için çok çeşitli bilgi ve davranışları kazanmaları gerekmektedir. Yani geleceğin müzik öğretmenlerinin müzik alan bilgisi ve bu bilgilerin öğretimine ilişkin mesleki bilgi yeterliklerine sahip olmaları (Kalyoncu, 2004:3) ayrıca Müzik eğitimi türlerine göre ve Eğitim-Okul Kademelerine göre çok çeşitli yeterliklere sahip olmaları (Uçan, 2006:83) büyük bir öneme sahiptir. Müzik eğitimcilerinin bu yeterlikleri kazanmalarında nitelikli bir eğitim almaları temel bir etken olarak görülmektedir.

Müzik öğretmeni yetiştirme sürecindeki temel öğeler ise öğrenci, eğitimci, program, fiziksel imkân ve ders materyalleri olarak sayılabilir. $\mathrm{Bu}$ temel öğelerin yanında aile, sosyal çevre, internet vb. etkenlerde büyük bir yer ve öneme sahiptir ancak özellikle fiziksel imkân ve öğretmen yeterlikleri eğitimin niteliğini ve kalitesini direkt olarak etkilemektedir. Karasolak ve Sarı (2011) araştırmaları sonucunda, okulların genel görünümünün ve fiziki mekân uygunluğunun, eğitim-öğretim kalitesini etkilemede önemli bir faktör olduğu belirlenmiş ve okulların öğrenci ve öğretmenler için huzurlu, güven verici, çalışma motivasyonunu arttırıcı nitelikte olabilmesi için, okul binalarının daha yaşanılabilir mekânlar olarak düzenlenmesi için gereken önlemlerin alınması gerektiği vurgulanmıştır (s.132).

Kara ve Yetkin (2015) çalışmalarında fiziksel imkânları yeterli olan bir sınıfta ders yapan öğretmenlerin kendilerini daha yeterli hissettikleri sonucuna ulaşmış (s. 1), Uludağ ve Odacı (2002) ise araştırmalarında fiziksel mekânın öğelerini; Öğrenci sayısı, renk, 1şık, 1sı, temizlik, gürültü, görünüm (Estetik) ve yerleşim düzeni olmak üzere sekiz maddede toplamış ve her birinin eğitimögretim sürecindeki yeri ve önemini vurgulamıştır (s.153-154). Karakaya ve Tiper (2013) ise araştırmalarında, okulların dış çevreleri olan okul bahçelerinin, çocukların sosyal, fiziksel, duygusal ve zihinsel becerilerini geliştirebilecekleri mekânlar olması nedeniyle bu mekânların fiziksel, sosyal ve psikolojik gereksinimleri cevap vermesinin önemini vurgulamışlardır (s.59). Ancak; Eğitim-öğretim sürecinde fiziksel imkânın büyük bir öneme sahip olmasına karşın çeşitli kademelerde ve illerde hizmet veren okulların fiziksel imkânlarının bazı özellikler açısında yetersiz olduğu yapılan çeşitli araştırmalar ile tespit edilmiştir (Karakütük, Tunç, Bülbül, vd. 2012), (Karaküçük, 2008), (Taşdan, Tösten, Bulut, vd. 2013).

Karahan'ın (2016a) araştırması sonucunda Türkiye'deki MEAD'larının fiziksel imkân ve ders materyallerinin bölgesel kapsamda dengeli bir dağılım göstermediği ve bazı MEAD’larının fiziksel imkânlarında kayda değer ölçüde yetersizliklerin olduğu belirlenmiştir. Eğitim-öğretim sürecini olumsuz yönde etkileyen bu soruna ek olarak akademik kadroların nicel yetersizliği de yıllardır çözülemeyen önemli bir sorundur. Karahan'ın (2016b) araştırması sonucunda Müzik Eğitimi Anabilim Dalı MEAD öğrenci sayıları ile akademik kadro sayılarının yedi bölge kapsamında dengeli bir dağılım göstermediği ve bu eşitsizliğin temel sebebinin MEAD’na alınacak öğrenci sayısının belirli bir standarda göre yapılmaması olduğu belirlenmiştir. Müzik eğitimcilerinin çok iyi bildiği ve yıllardır 
çözülemeyen bu sorun akademik kadro sayılarının öğrenci sayılarına oranla yetersiz kalmasına ve eğitimcilerin ders yüklerinin kayda değer ölçüde artmasına neden olmaktadır.

$\mathrm{Bu}$ iki çalışmanın sonuçları MEAD'nın binalarının fiziksel imkân yetersizliklerini ve akademisyenlerin sayısal yetersizliklerini açıç̧a göstermektedir. Bu iki önemli sorun aslında MEAD’na kabul edilecek öğrenci sayılarının ve MEAD binalarının belirlenmiş standartlara göre yapılmaması sebebiyle yaşanmaktadır ve ne yazık ki 2016 yılında olmamıza rağmen halen MEAD binalarının sahip olması gereken özelliklere ve standartlara ilişkin yapılan hiçbir çalışma bulunmamaktadir.

MEAD bina standartlarının belirlenebilmesi için öncelikle binaların kaç öğrenciye hizmet vereceğinin belirlenmesi gerekmektedir. Karahan'ın (2016b) yılında yaptığı çalışma sonucunda Türkiye genelinde eğitim-öğretim faaliyeti yapılan 25 MEAD’nda toplam 4004 öğrencinin eğitim aldığı belirlenmiştir. $\mathrm{Bu}$ araştırmanın sonuçlarına dayalı olarak toplam öğrenci sayısı 25 MEAD’na eşit olarak bölündüğünde ve bir MEAD’nın ortalama 160 öğrenciye hizmet vermesi gerektiği görülmektedir.

İkinci olarak ise, MÖLP'na göre öğrencilerin ders ve ders dış1 çalışma sürelerinin belirlenmesi ve bu sürelere göre ders ve ders dışı çalışmaların yapılacağı mekânların sayılarının belirlenmesi gerekmektedir. Ayrıca öğrencilerin ders ve ders dışı çalışma sürelerine ve akademisyen görüşlerine dayalı olarak MEAD binalarının bir haftada kaç gün ve hangi saatler arasında hizmet vermesi gerektiğinin de belirlenmesi gerekmektedir.

Yukarıda verilen bilgiler ışığında MEAD binalarının öğrenci sayısına ve MÖLP’na uygun olarak belirlenmiş bir standardının olmadığı ve bu sebeple MEAD binalarının birbirinden oldukça farklı fiziksel imkânlara sahip oldukları görülmektedir. Bu önemli sorunun çözümüne katk1 sağlamak amacıyla MEAD binalarının standartlarının bilimsel bir araştırma kapsamında belirlenmesi gerekli görülmüştür.

\section{Amaç ve Önem}

Araştırmanın amac1, yürürlükte olan MÖLP kapsamında 160 öğrenciye hizmet veren bir MEAD binasının sahip olması gereken Bireysel Piyano dersliği, Bireysel Piyano Çalışma odası, Bireysel Çalgı Dersliğii, Bireysel Çalgı Çalışma Odası, Orkestra Çalışma Salonu, Derslikler vb. fiziksel imkânların sayısal standartlarını belirlemek amaçlanmaktadır. Araştırma kapsamında bina standartlarının 160 öğrenciye göre oluşturulmasının amacı ise, Türkiye'de ihtiyaç duyulan bina standardının gerçek öğrenci sayısı üzerinden belirlenmesidir.

Araştırma, hem konuya ilişkin yapılan ilk çalışma olması hem de yürürlükte olan MÖLP'nın daha etkin kullanımına katkıda bulunması açılarından önem taşımaktadır. Araştırmanın amacına yönelik oluşturulan problem cümlesi aşağıda belirtilmiştir.

\section{Problem}

MÖLP kapsamında eğitim alan toplam 160 öğrenciye hizmet verecek bir MEAD binasında kaç adet piyano, bireysel çalgı, orkestra salonu vb. çalışma mekânına ihtiyaç vardır? 


\section{Alt Problem}

1. MÖLP'nda yer alan Piyano, Bireysel Çalgı ve Bireysel Ses Eğitimi derslerinin yapılabilmesi için kaç adet akademik personel odasına ihtiyaç vardır?

2. MEAD'nda öğrencilerin ders dışı çalgı ve ders dışı bireysel ses çalışmalarını (Piyano, Keman, Şan vb.) yapabilmeleri için kaç adet piyano çalışma odası ve bireysel çalgı çalışma odasına ihtiyaç duyulmaktadir?

3. MEAD’nda öğrencilerin MIOY, Eşlik, Armoni derslerinin uygulamalı ders dışı çalışmalarını yapabilmeleri için kaç adet piyano çalışma odasına ihtiyaç duyulmaktadır?

4. MÖLP'nda yer alan Orkestra/Oda Müziği ve Koro derslerinin yapılabilmesi için kaç adet orkestra, oda müziği ve koro salonuna ihtiyaç vardır?

5. MEAD'nda öğrencilerin küçük gruplar halinde Orkestra, Oda Müziği ve Koro ders diş1 çalışmalarını yapabilmeleri için kaç adet grup çalışma odasına ihtiyaç duyulmaktadır?

6. MEAD'nda öğrencilerin Elektronik Org ders dışı çalışmalarını yapabilmeleri için kaç adet elektronik org laboratuarına ihtiyaç duyulmaktadır?

7. MÖLP'nda yer alan Okul Çalgıları, Müzik Tarihi, Türkçe, İngilizce, Tarih vb. diğer tüm toplu derslerin yapılabilmesi için kaç adet dersliğe ihtiyaç vardır?

8. MEAD binaları bir haftada kaç gün ve günde kaç saat hizmet vermelidir?

9. MEAD binalarında derslikler dışında ne tür mekân ve imkânlara ihtiyaç duyulmaktadır?

\section{Yöntem}

Araştırma tarama modelinde betimsel bir çalışmadır. Tarama modelleri, geçmişte ya da halen var olan bir durumu var olduğu şekliyle betimlemeyi amaçlayan araştırma yaklaşımlarıdır ve araştırmaya konu olan olay, birey ya da nesne, kendi koşulları içinde ve var olduğu gibi tanımlanmaya çalışılır (Karasar, 2003: 77).

Araştırmaya önce kaynak taramasıyla başlanmış ve sonrasında araştırma kapsamında Türkiye'deki 28 Müzik Eğitimi Anabilim Dalı'nda görev yapan toplam 224 akademisyene bilgi formu uygulanmış 58 alan uzmanı akademisyen ile görüşme yapılmıştır.

Çalışma Evreni

Araştırmanın evrenini MÖLP kapsamında 160 öğrenciye hizmet verecek bir MEAD binasında kaç adet Bireysel Çalgı Odası, Derslik, Orkestra Salonu vb. mekânların olması gerektiğine ilişkin standartlar oluşturmaktadır.

Veri Toplama Araçları

Araştırma verilerinin bir bölümüne kaynak taraması yöntemiyle diğer bir bölümüne ise MEAD’nda görev yapan 224 akademisyene uygulanan bilgi formuyla ve 58 akademisyenle yapılan görüşme yöntemiyle ulaşılmıştır. Verilerin işlenmesinde metin analizi yöntemi ve SPSS 22 programı kullanılmış ve sonuçlar yüzde değerleri üzerinden yorumlanmıştır. 


\section{Bulgular}

Araştırmanın alt problemlerine ilişkin bulgular ve bu bulgulara ait tablolara aşağıda yer verilmiştir.

Tablo 1. Piyano, Bireysel Çalgl ve Bireysel Ses Eğitimi derslerinin yapılabilmesi için gereken akademik personel odalarının sayısı.

\begin{tabular}{|c|c|c|c|}
\hline & Akademisyenlerin & \multirow{3}{*}{$\begin{array}{l}\text { Yapılması } \\
\text { gereken } \\
\text { ders saati } \\
\text { toplamı }\end{array}$} & \multirow{3}{*}{$\begin{array}{lr}\text { Dersin } & \text { yapılması } \\
\text { için } & \text { gereken } \\
\text { akademisyen oda } \\
\text { sayısı }\end{array}$} \\
\hline & Girdiği Bireysel & & \\
\hline & $\begin{array}{l}\text { Derslerin Haftalık } \\
\text { ders saati toplamı }\end{array}$ & & \\
\hline Piyano & 20 saat & 160 saat & 8 oda \\
\hline Bireysel Çalgı & 20 saat & 160 saat & 8 oda \\
\hline Bireysel Ses Eğitimi & 20 saat & 160 saat & 8 oda \\
\hline Toplam & 60 saat & 480 saat & 24 oda \\
\hline
\end{tabular}

Araştırmada alan uzmanlarıyla yapılan görüşmelerde Bireysel olarak yapılan çalgı dersleri kapsamında bir eğitimcinin bir haftada en fazla 20 saat derse girmesinin uygun olduğu daha fazla derse girilmesi durumunda öğrencilerin gerektiği gibi takip edilmesinin oldukça güçleştiği dersin başarı düzeyini düşürdüğü yönünde görüş belirtmişlerdir. Bu bulguya göre tablo 1 incelendiğinde, MÖLP'nda yer alan Piyano, Bireysel Çalg1 ve Bireysel Ses eğitimi derslerinin haftada toplam 480 saat bireysel olarak yapılabilmesi için 24 akademik personele ve MEAD binasında 24 adet akademisyen odasına ihtiyaç olduğu belirlenmiştir.

Tablo 2. Öğrencilerin ders dışı çalgı ve ders dışı bireysel ses çalışmalarını (Piyano, Keman, Şan vb.) yapabilmeleri için gereken piyano çalışma odası ve bireysel çalgı çalışma odası sayıları.

\begin{tabular}{|c|c|c|c|}
\hline & Piyano & Bireysel Çalgı & Bireysel Ses Eğitimi \\
\hline $\begin{array}{l}\text { Bir öğrencinin } \\
\text { ders dışı çalışma gün sayısı }\end{array}$ & 6 & 6 & 5 \\
\hline $\begin{array}{l}\text { Bir öğrencinin } \\
\text { ders dışı çalışma süresi } \\
\text { (dakika) }\end{array}$ & 92.8 dak. & 116 dak. & 47 dak. \\
\hline $\begin{array}{l}160 \text { öğrencinin } \\
\text { ders dışı çalışma süresi } \\
\text { (dakika) }\end{array}$ & $\begin{array}{l}14.848 \\
\text { dak. }\end{array}$ & 18.560 dak. & 7.520 dak. \\
\hline $\begin{array}{l}160 \text { öğrencinin } \\
\text { ders dışı çalışma süresi (saat) }\end{array}$ & 247,4 saat & 309,3 saat & 125,3 saat \\
\hline $\begin{array}{l}\text { Ders dışı çalışmaları için } \\
\text { gereken çalışma odası sayısı }\end{array}$ & 17 adet & 21 adet & 9 adet \\
\hline
\end{tabular}

Araştırma kapsamında uygulanan bilgi formunda Piyano, Bireysel Çalgı ve Bireysel Ses Eğitimi derslerini yürüten alan uzmanlarına öğrencilerin bu dersler kapsamındaki ders dışı çalışma süreleri sorulmuş ve akademisyenlerin belirttikleri sürelerin aritmetik ortalaması alınmıştır. Bu sonuçlara göre tablo 4 incelendiğinde bir öğrencinin günlük ders dışı piyano çalışma süresinin 92,8 dakika, 160 öğrencinin ise 14.848 dakika yani 247 saat olması gerektiği, bir öğrencinin günlük Bireysel Çalgı ders dışı çalışma süresinin 116 dakika, 160 öğrencinin ise 18.560 dakika yani 309 saat olması gerektiği ve bir öğrencinin günlük Bireysel Ses Eğitimi ders dışı çalışma süresinin 47 dakika, 160 öğrencinin ise 7.520 dakika yani 125 saat olması gerektiği belirlenmiştir. 
Tablo 9'daki bulgulara göre MEAD binalarının 08:00-23:00 saatleri arasında 15 saat süreyle hizmet verdiği düşünüldüğünde; Öğrencilerin ders dışı piyano çalışmalarını yapabilmeleri için MEAD binasında en az 17 adet piyano çalışma odasına, en az 21 adet Bireysel Çalgı çalışma odasına ve en az 9 adet Bireysel Ses çalışma odasına ihtiyaç duyulmaktadır.

Tablo 3. Öğrencilerin MIOY, Eşlik, ve Armoni derslerinin uygulamalı ders dışı çalışmalarını yapabilmeleri için gereken piyano çalışma odası sayısı.

\begin{tabular}{|c|c|c|c|}
\hline & \multicolumn{3}{|c|}{ Toplam Süre } \\
\hline & MIOY & Eşlik & Armoni \\
\hline Öğrencilerin piyano odalarını haftalık & $\% 84,6$ & $\% 77,8$ & $\% 87,4$ \\
\hline kullanma gün sayıları & 5 gün & 3 gün & 2 gün \\
\hline $\begin{array}{l}\text { Bir öğrencinin piyano odalarını günlük } \\
\text { kullanma süresi }\end{array}$ & 21,1 dak. & 40,4 dak. & $\begin{array}{l}31,3 \\
\text { dak. }\end{array}$ \\
\hline $\begin{array}{l}160 \text { öğrencinin piyano odalarını günlük } \\
\text { kullanma süreleri toplamı }\end{array}$ & 56,2 saat & 107,7 saat & 83,4 saat \\
\hline $\begin{array}{l}\text { İhtiyaç duyulan piyano odası sayısı } \\
\text { toplamı }\end{array}$ & 4 adet & 8 adet & 6 adet \\
\hline Oda sayısı genel toplam & 18 adet & & \\
\hline
\end{tabular}

Tablo 3'de öğrencilerin piyano odalarını kullanma gün sayılarına ilişkin akademisyen görüşleri ağırlıklı yüzde ortalamalar üzerinden gösterilmiş, günlük çalışma sürelerinin ise ise aritmetik ortalaması alınmıştır. Böylece akademisyen görüşler ve akademisyen görüşlerine dayalı olarak belirlenecek olan piyano çalışma odası sayılarına ilişkin tüm veriler tablo 3'de belirtilmiştir.

Tablo 3 incelendiğinde akademisyenlerin \% 84,6'sı öğrencilerin MİOY ders dışı çalışmalarını haftada 5 gün, akademisyenlerin \% 77,8'i öğrencilerin Eşlik ders dışı çalışmalarını haftada 3 gün ve akademisyenlerin \% 87,4'’ü öğrencilerin Armoni ders dışı çalışmalarını haftada 2 gün yapması yönünde görüş belirtmiştir. Öğrencilerin günlük çalışma sürelerine ilişkin aritmetik ortalama sonuçları incelendiğinde bir öğrencinin MİOY ders dişı günlük çalışma süresinin 21,1 dakika (160 öğrenci toplamı 56,2 saat) olduğu, Eşlik ders dışı günlük çalışma süresinin 40,4 dakika (160 öğrenci toplamı 107,7 saat) olduğu ve Armoni ders dış1 günlük çalışma süresinin 31,3 dakika (160 öğrenci toplamı 83,4 saat) olduğu belirlenmiştir.

Tablo 3 incelendiğinde öğrencilerin MIOY ders dışı çalışmalarını haftanın 5 günü toplam 56,2 saat yapabilmeleri için MEAD binasında en az 4 adet piyano çalışma odasına ihtiyaç olduğu, Eşlik ders dışı çalışmalarını haftanın 3 günü toplam 107,7 saat yapabilmeleri için en az 8 adet piyano çalışma odasına ihtiyaç olduğu ve Armoni ders dışı çalışmalarını haftanın 2 günü toplam 83,4 saat yapabilmeleri için MEAD binasında en az 4 adet piyano odasına genel toplamda ise en az 18 adet piyano çalışma odasına ihtiyaç olduğu belirlenmiştir.

Tablo 4. Orkestra, Oda Müziği ve Koro derslerinin yapılabilmesi için gereken salon sayısı.

\begin{tabular}{lll}
\hline & $\begin{array}{l}\text { Ders } \\
\text { Saati }\end{array}$ & $\begin{array}{l}\text { Salon } \\
\text { Sayısı }\end{array}$ \\
\hline $\begin{array}{l}\text { V-VII. Güz Dönemi Orkestra Derslerinin haftalık ders saati toplamı } \\
\text { V-VII. Güz Dönemi Oda Müziği Derslerinin haftalık ders saati }\end{array}$ & 6 saat & 1 adet \\
toplamı & & \\
$\begin{array}{l}\text { III-V-VII. Güz Dönemi Koro Derslerinin haftalık ders saati } \\
\text { Güz Dönemi Toplamı }\end{array}$ & $\begin{array}{l}11 \text { saat } \\
\mathbf{2 3} \text { saat }\end{array}$ & \begin{tabular}{l} 
6 adet \\
\hline
\end{tabular}
\end{tabular}




\section{VI-VIII. Bahar Dönemi Orkestra Derslerinin haftalık ders saati 6 saat 1 adet toplamı \\ VI-VIII. Bahar Dönemi Oda Müziği Derslerinin haftalık ders saati 6 saat 1 adet toplamı

$\begin{array}{lll}\text { II-IV-VI-VIII. Bahar Dönemi Koro Derslerinin haftalık ders saati } & 11 \text { saat } & 1 \text { adet } \\ \text { Bahar Dönemi Toplamı } & \mathbf{2 3} \text { saat } & \mathbf{6} \text { adet }\end{array}$

MÖLP incelendiğinde Orkestra/Oda Müziği derslerinin 5. dönemden 8. döneme kadar toplamda 4 dönem devam ettiği ve V-VII Güz Dönemi toplamında haftada 6 saat ve VI-VIII Bahar Dönemi toplamında haftada 6 saat olarak yapıldığı görülmektedir. MÖLP'ında Orkestra/Oda Müziği dersinin tek bir ders gibi göründüğü ancak bu dersin iki ayrı ders olarak yapıldığı bilinen bir durumdur. Araştırmada alan uzmanı akademisyenlerle yapılan görüşme sonucunda 40 kişilik öğrenci grubunun genel olarak 25 öğrenci Orkestra 15 öğrenci Oda Müziği olmak üzere iki ayrı gruba bölündüğü ve derslerin genel olarak aynı gün ve aynı saatte yapılması sebebiyle iki ayrı salona ihtiyaç olduğu belirlenmiştir. Bu bulgulara dayalı olarak Orkestra ve Oda Müziği dersinin yapılabilmesi için MEAD binasında en az 1'er adet salona ihtiyaç olduğu belirlenmiştir.

MÖLP incelendiğinde Koro derslerinin ise II. dönemden başlayıp VIII. döneme kadar toplam VII dönem sürdüğü ve dersin II-IV-VI-VIII. Bahar Dönemi toplamında 11 saat ve III-V-VII. Güz Dönemi toplamında 11 saat olarak yapıldığı görülmektedir. Bu durumda Koro dersini Bahar döneminde 160 öğrencinin, Güz Döneminde ise 120 öğrencinin aldığı görülmektedir. Bu bulgulara dayalı olarak Koro derslerinin yapılabilmesi için Güz ve Bahar dönemleri kapsamında MEAD binasında en az 1 adet koro salonuna ihtiyaç olduğu belirlenmiştir.

Tablo 5. Öğrencilerin grup olarak Orkestra, Oda Müziği ve Koro ders dışı çalışmalarını yapabilmeleri için gereken çalışma salonu sayısı.

\begin{tabular}{|c|c|c|c|c|c|}
\hline & $\begin{array}{l}\text { Tüm Sınıfların } \\
\text { Toplamında } \\
\text { Dersi Alan } \\
\text { Öğrenci } \\
\text { Sayısı }\end{array}$ & $\begin{array}{l}\text { Haftalık } \\
\text { Ders } \\
\text { Dışı } \\
\text { Çalışma } \\
\text { Süresi }\end{array}$ & $\begin{array}{l}\text { Gruplardaki } \\
\text { Öğrenci } \\
\text { Sayıları }\end{array}$ & $\begin{array}{l}\text { Grup } \\
\text { Sayıları }\end{array}$ & $\begin{array}{l}\text { Çalışma } \\
\text { Salonu } \\
\text { Sayısı }\end{array}$ \\
\hline Orkestra Çalışmaları & 50 öğrenci & 3 saat & 25 öğrenci & 2 & 1 \\
\hline Oda Müziği Çalışmaları & 60 öğrenci & 2 saat & 4 & 15 & 1 \\
\hline Koro Çalışmaları (Güz) & 160 öğrenci & 2 saat & 10 & 16 & 2 \\
\hline Koro Çalışmaları (Bahar) & 120 öğrenci & 2 saat & 10 & 12 & 2 \\
\hline
\end{tabular}

Tablo 5 incelendiğinde alan uzmanlarıyla yapılan görüşme sonucunda Orkestra derslerinin ders diş1 çalışmalarının haftada 3 saat süreyle yapılması gerektiği, Oda Müziği ve Koro ders dışı çalışmalarının haftada 2 saat süreyle yapılması gerektiği görülmektedir.

Tablo 4 kapsamındaki bulgulara dayalı olarak tablo 5 incelendiğinde ise, Orkestra ders dişı çalışması yapacak olan öğrenci sayılarının tüm sınıflar toplamında 50 kişi olduğu, toplamda 25 öğrenciden oluşan iki grubun her hafta 3 saat süreyle ders dışı çalışması yapabilmesi için MEAD binasında en az 1 adet orkestra çalışma salonuna ihtiyaç olduğu ve Orkestra derslerinin yapıldığ 1 salonun ders dış1 çalışmalar için yeterli olduğu belirlenmiştir.

Tablo 5 incelendiğinde Oda Müziği derslerini tüm sinıflar toplamında 60 öğrencinin aldığ ve 4'er kişiden oluşan 15 çalışma gurubunun olduğu görülmektedir. Öğrencilerin ders dışı Oda Müziği 
çalışmalarını yapabilmeleri için gerekli planlamanın yapılması durumunda MEAD binasında 1 adet Oda Müziği çalışma salonuna ihtiyaç olduğu ve Oda Müziği derslerinin yapıldığı salonun ders dış1 çalışmalar için yeterli olduğu belirlenmiştir.

Tablo 5 incelendiğinde Koro derslerini ise Güz Döneminde tüm sınıflar toplamında 160 öğrencinin aldığı ve 10'ar kişiden oluşan 16 çalışma gurubunun olduğu görülmektedir. Öğrencilerin ders diş1 Koro çalışmalarını yapabilmeleri MEAD binasında en az 1 adet Koro çalışma salonuna ihtiyaç olduğu ve Koro derslerinin yapıldığı salonun ders dışı çalışmalar için yeterli olduğu belirlenmiştir.

Tablo 5 incelendiğinde Koro derslerini ise Bahar Döneminde tüm sinıflar toplamında 120 öğrencinin aldığ1 ve 10 'ar kişiden oluşan 12 çalışma gurubunun olduğu görülmektedir. Öğrencilerin ders dış1 Koro çalışmalarını yapabilmeleri MEAD binasında en az 1 adet Koro çalışma salonuna ihtiyaç olduğu ve Koro derslerinin yapıldığı salonun ders dışı çalışmalar için yeterli olduğu belirlenmiştir.

Tablo 6. Elektronik Org derslerinin yapılabilmesi için gereken Elektronik Org Laboratuarı sayısı.

\begin{tabular}{lllll}
\hline & Haftalık & Her Öğrencinin & Tüm Öğrencilerin & Derslik \\
& Ders & Ders Dıșı Çalışma & $\begin{array}{l}\text { Ders Dıșı Çalışma } \\
\text { Sayısı }\end{array}$ & \\
& Saati & Süresi & Süresi & 1 adet \\
\hline Elektronik Org Dersi & 2 saat & 40 dak. & 160 dak. & 1 . \\
\hline
\end{tabular}

MÖLP incelendiğinde Elektronik Org dersinin sadece 4. yarıyılda ve haftada 2 saat yapıldı̆̆ yani dersi her dönem sadece 40 öğrencinin aldığı görülmektedir. Ayrıca akademisyenlerle yapılan görüşme sonucunda her öğrencinin ders dışı Elektronik Org çalışmalarını 40 dakika süreyle yapması gerektiği ve 40 öğrenci toplamında bu sürenin 160 dakika yani 2,66 saat olduğu belirlenmiştir. Ayrıca akademisyenler derslerin en az 20 adet elektronik Org ve 40 adet kulaklığa sahip bir Elektronik Org Laboratuarında yapılması gerektiğini belirtmişlerdir.

Yukarıdaki ve tablo 6'daki bulgulara dayalı olarak MEAD binasında akademisyenlerin belirttikleri imkânlara sahip en az 1 adet laboratuarın hem derslerin yapılması için hem de öğrencilerin ders dışı çalışmalarını yapılabilmeleri için gerekli olduğu belirlenmiştir.

Tablo 7. MÖLP'de yer alan Okul Çalgıları, Müzik Tarihi vb. alan derslerinin ve Türkçe, İngilizce vb. diğer toplu derslerin yapılabilmesi için gereken derslik sayısı.

\begin{tabular}{|c|c|c|c|c|}
\hline \multirow[t]{2}{*}{ MÖLP'de yer alan toplu dersler } & $\begin{array}{l}\text { Ders } \\
\text { Toplamı }\end{array}$ & Saati & \multicolumn{2}{|c|}{ Derslik Sayısı } \\
\hline & $\begin{array}{l}\text { Güz } \\
\text { Dönemi }\end{array}$ & $\begin{array}{l}\text { Bahar } \\
\text { Dönemi }\end{array}$ & $\begin{array}{l}\text { Güz } \\
\text { Dönemi }\end{array}$ & $\begin{array}{l}\text { Bahar } \\
\text { Dönemi }\end{array}$ \\
\hline $\begin{array}{l}\text { Toplu alan derslerinin haftalık ders } \\
\text { saati }\end{array}$ & 45 saat & 34 saat & 2 adet & 1 adet \\
\hline Toplu diğer derslerin haftalık ders saati & 26 saat & 29 saat & 1 adet & 1 adet \\
\hline Toplam & 71 saat & 63 saat & 3 adet & 2 adet \\
\hline
\end{tabular}

Tablo 7 incelendiğinde MÖLP kapsamındaki toplu alan derslerinde güz döneminde bir haftada 45 saat ders yapıldığı, bahar döneminde ise bir haftada 34 saat ders yapıldığı görülmektedir. Bu alan derslerinin yapılabilmesi için MEAD binasında güz dönemi için en az 2 adet dersliğe, bahar dönemi için ise en az 1 adet dersliğe ihtiyaç olduğu görülmektedir. Diğer dersler için ise güz ve bahar dönemi için en az 1 adet dersliğe ihtiyaç olduğu belirlenmiştir. 
Tablo 8. MEAD binalarının bir hafta kapsamında hizmet verme gün sayısına ilişkin akademisyen görüşleri.

\begin{tabular}{llllllll}
\hline & \multicolumn{3}{l}{$\mathbf{5}$ gün } & \multicolumn{3}{l}{ 6 gün } & \multicolumn{3}{l}{$\mathbf{7}$ gün } \\
\cline { 2 - 8 } Açık kalma gün sayısına & $\mathbf{f}$ & $\mathbf{\%}$ & $\mathbf{f}$ & $\mathbf{\%}$ & $\mathbf{f}$ & $\boldsymbol{\%}$ \\
\cline { 2 - 8 } ilişkin akademisyen görüşleri & 6 & 2,67 & 31 & 13,83 & 187 & 83,48 \\
\hline
\end{tabular}

Tablo 8 incelendiğinde MEAD binalarının açık kalma gün sayısına ilişkin olarak akademisyenlerin \% 83,48 'inin 7 gün, \% 13,83'ünün 6 gün ve \% 2,67'sinin ise 5 gün hizmet vermesi yönünde görüş belirttikleri görülmektedir.

Tablo 9. MEAD binalarının açık kalma saatlerine ilişsin akademisyen görüşleri.

\begin{tabular}{llccccc}
\hline & & $\mathbf{0 8 : 0 0 - 1 8 : 0 0}$ & $\mathbf{0 8 : 0 0}-\mathbf{2 3 : 0 0}$ & $\mathbf{2 4}$ sat \\
\cline { 2 - 7 } Hafta içi açık kalma saatlerine & $\mathbf{f}$ & $\boldsymbol{\%}$ & $\mathbf{f}$ & $\boldsymbol{\%}$ & $\mathbf{f}$ & $\boldsymbol{\%}$ \\
\cline { 2 - 7 } ilişkin akademisyen görüşleri & 16 & $\mathbf{7 , 1 4}$ & 176 & $\mathbf{7 8 , 5 7}$ & 32 & $\mathbf{1 4 , 2 8}$ \\
\hline & $\mathbf{0 8 : 0 0 - 1 8 : 0 0}$ & $\mathbf{0 8 : 0 0 -}$ & $\mathbf{2 3 : 0 0}$ & $\mathbf{2 4}$ sat \\
\cline { 2 - 7 } Hafta sonu açık kalma saatlerine & $\mathbf{f}$ & $\boldsymbol{\%}$ & $\mathbf{f}$ & $\boldsymbol{\%}$ & $\mathbf{f}$ & $\boldsymbol{\%}$ \\
\cline { 2 - 7 } ilişkin akademisyen görüşleri & & $\mathbf{4 1 , 0 7}$ & 121 & $\mathbf{5 4 , 0 1}$ & 11 & $\mathbf{4 , 9 1}$ \\
\hline
\end{tabular}

Tablo 9 incelendiğinde MEAD binalarının hafta içi açık kalma saatlerine ilişkin olarak akademisyenlerin \% 14,28'inin 24 saat, \% 78,57'sinin 08:00-23:00 saatleri arasında ve 7,14'ünün ise 08:00-18:00 saatleri arasında hizmet vermesi yönünde görüş belirttikleri görülmektedir.

Tablo 9 incelendiğinde MEAD binalarının hafta sonu açı kalma saatlerine ilişkin olarak akademisyenlerin \% 4,91'inin 24 saat, \% 54,01'inin 08:00-23:00 saatleri arasinda ve \%41,07'sinin ise 08:00-18:00 saatleri arasında hizmet vermesi yönünde görüş belirttikleri görülmektedir.

Tablo 8 ve tablo 9'daki sonuçlara dayalı olarak MEAD binalarının haftanın 7 günü ve 08:00-23:00 saatleri arasında günde 15 saat süreyle hizmet vermesi gerektiği belirlenmiştir.

Akademisyenlerle yapılan görüşme sonucunda hem öğrencilerin hem de akademisyenlerin çalışma saatlerini kısıtlı bir zamana sıkıştırmamaları ve daha çok çalışabilmeleri açısından MEAD binalarının haftanın yedi günü hizmet vermesi gerektiği yönünde görüş belirtmişlerdir. Ayrıca araştırmada MÖLP kapsamında toplam 201 saat ders yapılması ve alan derslerinin ders dışı çalışmalarının ise toplam 2030 dakika yani 33,83 saat yapılması gerektiği belirlenmiştir. Bu bulgulara dayalı olarak MEAD binalarının toplamda 234,83 saat hizmet vermesi gerektiğini görülmektedir. MEAD binalarının hizmet verme sürelerinin 5 ya da 6 gün ile sınırlandırılması durumunda binaların oda ve salon sayılarının artırılmasına ihtiyaç olacağı için binanın yapım maliyenin artacağı açıktır. Tüm bulgular 1şığında MEAD binalarının haftanın 7 günü ve 08:00-23:00 saatleri arasında günde 15 saat süreyle hizmet vermesinin uygun olduğu görülmektedir. 
Tablo 10. MEAD'nda binalarında akademisyenlerin talep ettiği mekân ve imkânlar.

\begin{tabular}{lllll}
\hline Belirtilen mekân ve imkânlar & \multicolumn{3}{c}{ Evet } & \multicolumn{3}{c}{ Hayır } \\
\cline { 2 - 6 } & f & $\mathbf{\%}$ & f & \% \\
\hline MEAD binasında en az 1 adet Piyano Laboratuarı olmalıdır & 171 & 76,33 & 53 & 23,66 \\
MEAD binasında en az 1 adet Bilgisayar Laboratuarı olmalıdır & 147 & 65,62 & 77 & 34,37 \\
$\begin{array}{l}\text { MEAD binasında en az } \mathbf{1} \text { adet Uzaktan Eğitim Laboratuarı } \\
\text { olmalıdır }\end{array}$ & 152 & 67,85 & 72 & 32,14 \\
MEAD binasında en az 1 adet kantin olmalıdır & 187 & 83,48 & 37 & 16,51 \\
\hline
\end{tabular}

Tablo 10 incelendiğinde akademisyenlerin \%76,33'nün MEAD binalarında en az 1 adet Piyano Laboratuarı olması gerekli gördügü, \%65,62'sinin en az 1 adet Bilgisayar Laboratuarı olmasını gerekli gördüğü, \%67,85'inin en az 1 adet Uzaktan Eğitim Laboratuarı olmasını gerekli gördügü ve \%83,48'inin ise MEAD binasında en az 1 adet kantin olmasını gerekli görüdüğü belirlenmiştir.

Ayrıca akademisyenlerin bilgi formunda serbest olarak belirttikleri görüş ve düşünceleri ve alan uzmanlarıyla yapılan görüşme verilerinin metin analizi yöntemiyle incelenmesi sonucunda akademisyenlere göre, MEAD binası içinde 1 adet bilgisayar laboratuarına ihtiyaç olduğu, ve bu laboratuvardaki bilgisayarların her birine "Word, Excel" vb. temel programların yanında Finale, Sibelius, Cubase vb. müzik yazılım ve kayıt programlarının yüklenmesi gerektiği ve en az iki öğrenciye bir adet bilgisayarın düştüğü 1 adet laboratuar ortamının sağlanması gerektiği, bu laboratuarın ders dışında öğrencilerin bilgiye ulaşma ya da çeşitli araştırmalarını yapmaları için etkin olarak kullanılmaya devam etmesi gerektiği yönünde görüş belirttikleri,

MEAD binalarının ses ve akustik yalıtımın olması gerektiği, en az 1 adet Konser salonu ve ses kayıt stüdyosu olması gerektiği, binaya öğrencilerin ve akademisyenlerin kartlı bir sistemle girmelerinin yanında bina girişinde ve ortak kullanım alanlarında kameralı güvenlik sistemi ve bina girişinde güvenlik görevlisi olması gerektiği ve MEAD binası içinde ya da yakın çevresinde öğrenci ve akademisyenlerin yiyecek, içecek ihtiyaçlarının 08:00-20:00 saatleri arasında karşılanması gerektiği,

Geleceğin müzik eğitimcilerinin mesleki yaşantılarında müzik teknolojilerini etkin olarak kullanabilmeleri için çeşitli müzik teknolojilerinin teorik ve uygulamalı olarak kazandırılacağı en az 1 adet bilişim salonuna ihtiyaç olduğu ve bu salonlarda kayıt, teknolojik arabirim kullanımı, dinleme, müzik yazılımları ile proje üretimi, temel seviyede mikser tonlaması vb. konularda teorik ve uygulamalı bilgilerin kazandırılması gerektiği yönünde görüş belirtmişlerdir.

\section{Sonuçlar}

Araştırma sonucunda piyano derslerinin yapılabilmesi için MEAD binasında 8 adet Bireysel Piyano dersliğine ( 8 adet akademisyen odasına) ihtiyaç olduğu, öğrencilerin ders dışı piyano çalışmalarını yapılabilmeleri için MEAD binasında 17 adet Piyano Çalışma odasına ihtiyaç olduğu ve öğrencilerin MİOY, Eşlik ve Armoni ders dışı çalışmalarını yapılabilmeleri için 18 adet Piyano Çalışma odasına ihtiyaç olduğu, yani toplam olarak 35 adet piyano çalışma odasına ihtiyaç olduğu sonuçlarına ulaşılmıştır.

Bireysel Çalgı derslerinin yapılabilmesi için MEAD binasında en az 8 adet Bireysel Çalgı Dersliğine (8 adet akademisyen odası) ihtiyaç olduğu ve öğrencilerin ders dışı Bireysel Çalgı çalışmalarının yapılabilmeleri için 21 adet Bireysel Çalgı Çalışma odasına ihtiyaç olduğu, Bireysel Ses Eğitimi derslerinin yapılabilmesi için MEAD binasında en az 8 adet Bireysel Çalgı Dersliğine ihtiyaç olduğu 
ve öğrencilerin ders dışı Bireysel Ses Eğitimi çalışmalarını yapılabilmeleri için 9 adet Bireysel Ses Eğitimi Çalışma odasına ihtiyaç olduğu sonuçlarına ulaşılmıştır.

Orkestra derslerinin ve ders dışı çalışmalarının yapılabilmesi için 1 adet Orkestra Derslik/Çalışma Salonuna ihtiyaç olduğu, Oda Müziği derslerinin ve ders dışı çalışmalarının yapılabilmesi için MEAD binasında en az 1 adet Oda Müziği Derslik/Çalışma salonuna ihtiyaç olduğu, Koro derslerinin ve ders dışı çalışmalarının yapılabilmesi için MEAD binasında en az 1 adet Koro Derslik/Çalışma Salonuna ihtiyaç olduğu, sonuçlarına ulaşılmıştır.

MEAD binasında en az 1 adet bilgisayar laboratuarına ihtiyaç olduğu ve bu laboratuvardaki bilgisayarların her birine "Word, Excel" vb. temel programların yanında Finale, Sibelius, Cubase vb. müzik nota yazma ve kayıt programlarının yüklenmesi gerektiği ve en az iki öğrenciye bir adet bilgisayarın düştüğü bir laboratuar ortamının sağlanması gerektiği ve bu laboratuarın ders dışında öğrencilerin bilgiye ulaşma ya da araştırmalarını yapmaları için etkin olarak kullanılmaya devam etmesi gerektiği sonuçlarına ulaşılmıştır.

Okul Çalgıları, Müzik Tarihi vb. alan derslerinin ve Türkçe, İngilizce vb. diğer toplu derslerin yapılabilmesi için MEAD binasında toplam 3 adet dersliğe ihtiyaç olduğu sonuçlarına ulaşılmıştır. Ayrıca MEAD binalarında ses yalıtımı ve akustik yalıtımının mutlaka olması gerektiği, en az 1 adet konser salonuna ve stüdyoya ve 1 adet bilişim salonuna ihtiyaç olduğu, binaya girişlerin kartlı bir sistemle olması ya da mutlaka bina girişinde güvenlik görevlilerinin olması gerektiği, bina içinde ya da çevresinde öğrencilerin ve akademisyenlerin yiyecek ve içecek ihtiyaçlarının 08:00-20:00 saatleri arasında karşılanması gerektiği sonuçlarına ulaşılmıştır.

\section{Tartışma}

MEAD binalarının fiziksel imkânlarının ve ders materyal yeterliklerinin bölgesel kapsamda eşit bir dağılım ve bölgeler arasında kayda değer farklılıkların olduğu belirlenmiştir(Karahan, 2016a). Eğitimöğretim sürecinde fiziksel imkân yeterliklerinin öğrencilerin başarı ya da başarısızlıklarına 11 olmalarında temel bir etken olduğu yapılan çeşitli araştırmalarda vurgulanmıştır(Karakütük, Tunç, Bülbül, vd. 2012), (Karaküçük, 2008), (Taşdan, Tösten, Bulut, vd. 2013) ancak müzik eğitimcisi yetiştirme sürecinde fiziksel imkân yetersizlik sorunu yılladır çözülememektedir. Ayrıca MEAD bina yeterliklerinin bölgesel kapsamda dengeli bir dağılım göstermemesi ise, Türkiye genelinde eşit ya da yakın şartlarda müzik eğitimcisi yetiştiremediğimize ilişkin önemli bir gösterge olarak görülmektedir. Yıllardır çözülemeyen bu önemli sorun, aslında binaların belirlenmiş bir standarda göre yapılmaması sebebiyle yaşanmaktadır.

YÖK tarafından MEAD binalarının belirlenmiş standartlara uygun olarak inşa edilmesini zorunlu hale getiren bağlayıcı bir kararın olmayışı, ayrıca üniversitelerin özerkliklerine ve kurum yetkililerinin aldıkları farklı kararlara bağlı olarak MEAD binaları her üniversitede kayda değer ölçüde farklılıklar içermektedir. $\mathrm{Bu}$ farklılıklar bazı MEAD'larında eğitim-öğretimin neredeyse yapılamaz hale gelebileceği kadar düşük bir seviyede kalmasına neden olabilmektedir. Eğitim-öğretim sürecini direkt olarak olumsuz yönde etkileyen bu önemli sorunun en kısa zamanda çözülmesi gerekli görülmektedir.

Araştırmada Bireysel çalgı ve piyano çalışma odaları, derslikler vb. mekânların her birinin sahip olması gereken büyüklükler, tavan yükseklikleri, kap1 ve pencerelerin özellikleri, 1s1, 1şı ve nem miktarları vb. çok sayıdaki özellik çalışma evreni dışında tutulmuştur. Bu özelliklerin MEAD binalarının yapılacağı bölgelere ve illere göre değişiklikler (coğrafi ve kültürel vb.) göstermesi sebebiyle müzik eğitimi alanına ek olarak, akustik, mühendislik ve iç mimarlık alan uzmanlarından 
oluşan bir inceleme grubu ile her bir MEAD binasının bulunduğu bölge ve ile göre standartlarının alan araştırması yapılarak belirlenmesi uygun görülmüştür. Böylece, Türkiye genelinde tek tip bir bina yapılması yerine, farklı mimari özelliklere sahip olan (binanın yapılacağı ilin ve üniversitesinin mimari ve kültürel özelliklerini yansıtması) ancak Türkiye genelinde belirlenmiş standartlara da uygun olan binalar yapilabilecektir.

Güzel Sanatlar Liseleri uzun bir süredir belirlenmiş standartlara uygun binalarda eğitim-öğretim yapmaktadır. Alt kurumumuz olan Güzel Sanatlar Liselerinin bina standartları açısından MEAD'larından daha ileride olması ise son derece üzücü bir durumdur. Bu önemli sorunun çözümüne yönelik öneriler aşağıda belirtilmiştir.

\section{Öneriler}

Araştırma sonucunda MEAD binalarının öğrenci ve akademisyen sayısına bağlı olarak sahip olması gereken Bireysel çalgı ve piyano çalışma odaları, derslikler vb. mekânların kaç adet olması gerektiğine ilişkin sayısal standartlar ve mekân türleri belirlenmiştir. Eğitim-öğretim yapılan MEAD binalarının bu standartlara mümkün olduğunca uygun hale getirilmesi nitelikli müzik eğitimcisi yetiştirilmesi açısından büyük bir öneme sahiptir.

Araştırmanın çalışma evreni dışında tutulan MEAD binalarındaki Bireysel çalgı ve piyano çalışma odaları, derslikler vb. mekânların her birinin sahip olması gereken büyüklükler, tavan yükseklikleri, kap1 ve pencerelerin özellikleri, 1sı, 1şık ve nem miktarları vb. çok sayıdaki özelliğin bilimsel bir araştırma ile tespit edilmesi gerekmektedir. Türkiye'deki MEAD binalarının sahip olması gereken tüm standartlar belirlendikten sonra bu standartların YÖK tarafından tüm MEAD olan üniversitelere yazılı olarak iletilmesi ve var olan binaların bu standartlara uygun hale getirilmesi gerekmektedir.

\section{Kaynaklar}

Karaküçük A. S. (2008). Okul Öncesi Eğitim Kurumlarında Fiziksel/Mekansal Koşulların İncelenmesi: Sivas İli Örneği. C.Ü. Sosyal Bilimler Dergisi 32(2):307-320 14.05.2016 tarihinde alınmıştır.

http://uvt.ulakbim.gov.tr/uvt/index.php?cwid=9\&vtadi=TSOS\&c=ebsco\&ano=98328_865b304d3ce2f $7296582622 \mathrm{e} 0 \mathrm{a} 624563 \& ?$

Karahan, A. S. (2012). Müzik Eğitimi Anabilim Dalları Kapsamındaki Piyano Derslerinin Bireysel olarak Yapılma Durumu. 10. Müzik Eğitimi Sempozyumu Niğde. s.646-657

Kara, A., Yetkin, K. (2015). Algılanan Öğretmen Yeterliklerinin Sınıf Koşulları Açısından İncelenmesi. International Journal of Social Science 40 s.1-15 14.05.2016 tarihinde alınmıştır. http://www.jasstudies.com/Makaleler/1872622266_1Do\%C3\%A7.\%20Dr.\%20Ahmet\%20KAR A.pdf

Karahan, A. S. (2016a). Türkiye'deki Müzik Eğitimi Anabilim Dalı Binalarının Fiziksel İmkân ve Ders Materyallerinin Belirlenmesi. VIII. Uluslararası Eğitim Araştırmaları Kongresinde Sözlü Bildiri, Çanakkale 18 Mart Üniversitesi, Çanakkale.

Karahan, A. S. (2016b). Türkiye'deki Müzik Eğitimi Anabilim Dalı Akademik Kadrolarının Bölgelere Göre Dağılımı ve Sayısal Olarak Yeterlik Durumları. (Yayınlanmamış Makale Çalışması). 
Karakaya, B., Kiper, T. (2013). Edirne Kent Merkezinde Bazı İlköğretim Okul Bahçelerinin Peyzaj Tasarım İlkeleri Açısından Mevcut Durumun Değerlendirilmesi. Tekirdağ Ziraat Fakültesi Dergisi 2013,10(1):59-71 14.05.2016 tarihinde alınmıştır.

ds.b.ebscohost.com/eds/detail/detail?vid=8\&sid=7665cff5-1f0c-4d16-86f23964330192c9\%40sessionmgr102\&hid=114\&bdata=Jmxhbmc9dHImc210ZT11ZHMtbG12ZQ\% $3 \mathrm{~d} \% 3 \mathrm{~d} \# \mathrm{db}=\mathrm{uvt} \& \mathrm{AN}=157270$

Karasolak, K., Sarı, M. (2011). Mimari Özellikleri Farklı Okullardaki Öğrenci ve Öğretmenlerin Okullarının Binası Hakkındaki Görüşlerinin İncelenmesi. Çukurova Üniversitesi Eğitim Fakültesi Dergisi, 40(3):132-154

Karakütük, K., Tunç, B., Bülbül, T., Özdem, G., Taşdan, M., Çelilkkale, Ö., Bayram, A. (2012). The adequacy of physical conditions of public high schools in Turkey according to their sizes Ankara University, Journal of Faculty of Educational Sciences, 45(2):183-204 14.05.2016 tarihinde alınmıştır.

http://uvt.ulakbim.gov.tr/uvt/index.php?cwid=9\&vtadi=TSOS\&c=ebsco\&ano=178105_71fb738 da32a1c3a3af3f7896b4918c4\&?

Karasar, N. (2003). Bilimsel Araştırma Yöntemi. (12.Basım). Ankara: Nobel yayıncılık

Kalyoncu, N. (2004). "Müzik Öğretmenliği Yeterlikleri ve Güncel Müzik Öğretmenliği Lisans Programı" 1924-2004 Musiki Muallim Mektebinden Günümüze Müzik Öğretmeni Yetiştirme Sempozyumu, 7-10 Nisan, Süleyman Demirel Üniversitesi, Burdur. 10.05.2016 tarihinde muzikegitimcileri.net sitesinden alınmıştır. http://www.muzikegitimcileri.net/bilimsel/bildiri/NKalyoncu.pdf

Taşdan, M., Tösten, R., Bulut, K., Karakaya, V. (2013). Okul Profili Araştırması (Kars İli Örneği). Atatürk Üniversitesi Sosyal Bilimler Enstitüsü Dergisi 17 (1):203-222 14.05.2016 tarihinde alınmıştır.

http://eds.b.ebscohost.com/eds/pdfviewer/pdfviewer?sid=7665cff5-1f0c-4d16-86f2-

3964330192 c9\%40sessionmgr102\&vid=23\&hid=114

Uçan, A. (2006). Müzik Öğretmenliği Yeterlikleri, Ulusal Müzik Eğitimi Sempozyumu, 26-28 Nisan, Pamukkale Üniversitesi, Denizli.

Uludağ, Z., Odac1, H. (2002). Eğitim Öğretim Faaliyetlerinde Fiziksel Mekan, Milli Eğitim Dergisi, s. 153-154. 14.05.2016 tarihinde alınmıştır.

http://dhgm.meb.gov.tr/yayimlar/dergiler/Milli_Egitim_Dergisi/153-154/uludag.htm

\section{Extended Abstract}

\section{Introduction}

The basic elements in the music teacher education process are considered to be as students, academicians, the program, physical facilities and course materials. In addition to these basic elements, family, social environment, the internet and so on also play great importance but especially physical facilities and teachers' qualifications directly affect the quality of education. Physical facilities and course materials have a great place and importance in the training process of music 
teachers; however, as a result of the literature review, it was found out that physical facilities of buildings at the Departments of Music Education in Turkey did not have an equal distribution regionally and had various inadequateness, because there were no standards for the buildings of Music Education Departments.

As a result of the literature review, it was found out that there were no studies regarding the standards of the buildings of Music Education Departments. Firstly, the number of the students to have education should be determined in order to determine these standards. As a result of the literature review, it was found out that in total 4004 students had education at 25 Music Education Departments in Turkey. The total number of students was equally divided among 25 Music Education Departments and it was determined that nearly 160 students had education in one Music Education Department.

Secondly, in order to determine the standards of the buildings, students' in and out- of-class study time and the number of places for the students' in and out-of-class studies according to their study time should be determined. In addition, that how many days in a week and when and what time the buildings would be used should be determined according to the opinions of the academicians and students' study time.

In the light of the information given above, it was found out that there were no standards for the buildings set according to the number of students and Music Education Undergraduate Program and thus, the buildings of Music Education Departments had quite different physical facilities from each other. In order to contribute to the solution of this important problem, the standards of the buildings of the Music Education Departments were considered to be determined within the scope of a scientific research.

Purpose

The aim of the present research is to determine features of the buildings of the Music Education Departments according to the needs of 160 undergraduate music students and to determine the standards of these features. The reason why the standards of the building were constituted according to 160 students was to determine the needed standards of the building according to the actual number of students. The research is important for being the first study on the subject and for its contribution to more effective use of the present Music Education Undergraduate Program.

\section{Method}

Research population includes the standards about the needed Instrument Rooms, Classrooms, Orchestra Halls and etc. places at a Department of Music Education for 160 undergraduate music students. In the research in which the descriptive survey model was preferred, some of the data were obtained through literature review and the others via the telephone interview.

Research started with literature review and then 224 academicians working at 28 Music Education Departments in Turkey were applied an information form and 58 academicians were interviewed. For the process of data, text analysis method and SPSS 22 program were used and the results were commented as frequency and percentage values.

\section{Conclusion and Discussion}

As a result of the study, it was concluded that there should be 8 Individual Piano Classes ( 8 academician rooms), 17 Piano Rooms for students' out-of-class activities, and 18 Piano Rooms for 
extracurricular Ear Training, Accompaniment and Harmony courses. In other words, there should be 35 Piano Rooms. It was also concluded that for Individual Instrument courses, there should be 8 Individual Instrument Classes (8 academician rooms) and 21 Individual Instrument Rooms for students' out-of-class activities, 8 Individual Instrument Classes for Individual Voice Training courses, and 9 Individual Voice Training Rooms for students' out-of -class Individual Voice Training studies. Another result was that 1 Orchestra Class/ Room was needed for Orchestra courses and out-of-class activities, 1 Chamber Music Class/Room was needed for Chamber Music courses and out-of-class activities, and 1 Choir Class/Room was needed for Choir courses and out-of-class activities.

Moreover, it was concluded that there should be at least 1 Computer Lab. and each of the computers in the lab should have programs for musical notes writing and recording such as Finale, Sibelius, Cubase etc. in addition to basic programs such as "Word, Excel" and etc. There should be at least one computer for two students in the lab and this lab can be easily used by the students whenever they need.

Finally, it was determined that there should be 3 classrooms for the courses such as Music History, Turkish and English. In addition, the sound insulation and acoustic insulation were necessary. There should be at least 1 Concert Hall and Studio, and 1 IT Room. There should be a card entry system or a security staff at the entrance of the building. In or around the building, there should be places to meet the needs of the students and the academicians between 8:00 am and $8 \mathrm{pm}$. 